\title{
Caregiver Burden and Quality of Life in Early and Late Stages of Idiopathic Parkinson's Disease
}

\author{
Fatma Genç ${ }^{\bowtie}$, Burcu Yuksel, and Firdevs Ezgi Ucar Tokuc \\ Department of Neurology, Antalya Training and Research Hospital, Antalya, Turkey
}

\begin{abstract}
Objective Idiopathic Parkinson's disease (IPD) is a chronic progressive neurodegenerative movement disorder characterized by motor and non-motor symptoms that affects patients' quality of life and caregiver burden. The aim of our study was to assess the caregiver burden (CB) in early and late stages of disease and to search if there was a relationship between quality of life and CB.

Methods A total of 74 patients who were diagnosed as having IPD by a movement disorder neurologist according to United Kingdom Brain Bank Criteria and their caregivers were randomly selected for participation the study. Staging of PD was performed by the neurologist based on the Hoehn and Yahr (H\&Y) Scale. Disease severity was determined using the Unified Parkinson's Disease Rating Scale (UPDRS). CB was evaluated using the Zarit Caregiver Burden Inventory (ZCBI). The Hospital Anxiety and Depression Scale (HADS) and the Beck Depression Inventory (BDI) were used to assess anxiety and depressive symptoms in patients with IPD and their caregivers. The Short-Form Health Survey instrument (SF-36) was used to evaluate quality of life of the patients. The Mini-Mental State Examination (MMSE) was administered to patients to evaluate gross cognitive status.

Results Seventy-four patients (male, 58.1\%) were included in the study. The mean age of patients was $66.18 \pm 8.5$ and the mean duration of disease was $67.23 \pm 41.8$ months. According to the H\&Y scale, the patients were divided into two groups; stage I-II as early stage and stage III-V as late stage. Group 1 (H\&Y I-II) consisted of 40 patients, and group 2 (H\&Y III-V) comprised 34 patients. The mean duration of disease and UPDRS scores were significantly higher in group $2(\mathrm{p}=0.003, \mathrm{p}=0.001$, respectively). Significant differences were found in group 2 according to BDI. There were significant differences between group 1 and 2 according to SF-36 subdomains such as general health, emotional role, social functioning, pain, and mental health $(\mathrm{p}=0.019, \mathrm{p}=0.038, \mathrm{p}=0.005, \mathrm{p}=0.004, \mathrm{p}=0.014$, respectively). However, there were no significant differences between these two groups concerning CB.

Conclusion Although CB was found in 35 (47.3\%) caregivers in our study, we found no significant differences between the caregivers of patients with early and late-stage IPD patients. We thought that this might be due to strong family relationships and cultural dynamics in Turkey. Burden was found to be higher in depressive patients' CGs and CGs who had depressive symptoms. It is important to recognize depressive symptoms earlier to protect the relationship between the CG and the patient because the main providers of care are family members.

Psychiatry Investig 2019;16(4):285-291
\end{abstract}

Key Words Parkinson's disease, Caregiver, Caregiver burden, Depression, Quality of life.

\section{INTRODUCTION}

Idiopathic Parkinson's disease (IPD) is a chronic progressive neurodegenerative movement disorder characterized by motor and non-motor symptoms. Due to its progressive debilitating nature, it negatively affects caregivers rather than

\footnotetext{
Received: December 26, 2018 Revised: February 11, 2019

Accepted: February 20, 2019

$\triangle$ Correspondence: Fatma Genç, MD

Department of Neurology, Antalya Training and Research Hospital, Varlık Mah. Kazım Karabekir Cad. Antalya Eğitim ve Araştırma Hastanesi Nöroloji Kliniği Muratpaşa/ANTALYA, Antalya 07100, Turkey

Tel: +90 242249 4400, Fax: +90 24224944 87, E-mail: sanivardr@yahoo.com

(a) This is an Open Access article distributed under the terms of the Creative Commons Attribution Non-Commercial License (https://creativecommons.org/licenses/by$\mathrm{nc} / 4.0$ ) which permits unrestricted non-commercial use, distribution, and reproduction in any medium, provided the original work is properly cited.
}

patients. ${ }^{1-4}$ In recent years, due to the extended human life span, an increased prevalence of IPD has been encountered and that seems to cause individual and social problems related to caregiving. ${ }^{2}$ As disease progresses, the disability increases, then patients require more care and assistance for performing daily activities. Family members of patients usually assume primary responsibility for this burden., ${ }^{1,2}$ Motor problems, mood disturbances, communication difficulties, impaired sexual and autonomic functioning also increase when the disease progresses and these problems may lead to economic consequences, the loss of employment, disruption in family roles, stigmatization, and coping with increasing difficulties in physical and mental disability. ${ }^{5}$ Consequently, daily caregiving of patients with IPD can induce stress, frustration, tension, and 
a feeling of insecurity on caregivers. ${ }^{6}$

Caregiver burden (CB) can be defined as the strain or load borne by a person who cares for a chronically ill, disabled or elderly family member. ${ }^{7}$ The duration and the stage of the disease, motor and non-motor symptoms, additional neuropsychiatric symptoms and adverse effects of medications can affect CB. ${ }^{1,6}$ It has been described as all negative effects associated with the caregiving experience of chronic illnesses that cause physical, mental, and socioeconomic consequences. ${ }^{8}$

In Turkey, the caregivers of these patients are usually their family members, mostly their children or spouses. Their emotional and physical support prevents early admission in a nursing home and the disabling condition causes psychosocial and economic burden on their caregivers who were not trained formally in caregiving. ${ }^{9}$

Accordingly, the aim of this study was to assess the impact of early and advanced stage of IPD on caregivers' burden and to emphasize the importance of early prevention of caregivers' observable or subjective burden.

\section{METHODS}

\section{Study participants and design}

A total of 74 patients who were diagnosed as having IPD by a movement disorder neurologist according to United Kingdom Brain Bank Criteria and their caregivers were randomly selected for participation in this study. Spouses (wife or husband), children (son or daughter), and paid CGs were the main categories inside the group of CGs. Demographic data were collected from both groups. History of severe systemic diseases (e.g. malignancy, severe arthrosis), severe stroke, dementia, epilepsy and other comorbid diseases (e.g. blindness, extremity amputation or psychiatric diseases) were excluded.

Staging of PD was performed by the neurologist based on the Hoehn and Yahr (H\&Y) Scale; stage I and II were considered as early stage, and stage III, IV, and V as the late stage of the disease. ${ }^{10}$ Disease severity was determined using the Unified Parkinson's Disease Rating Scale (UPDRS).

$\mathrm{CB}$ was evaluated using the Zarit Caregiver Burden Inventory (ZCBI), which contains 22 items that measure the impact of the disease on caregiver's physical, emotional, social, and financial status. ${ }^{11}$ The responses range from 0 (never) to 4 (nearly always), the maximum score is 88 , and higher scores indicate higher burden. The ZCBI total score was also categorized as follows: 0-20 (little or no burden), 21-40 (mildto-moderate burden), 41-60 (moderate-to-severe burden), and 61-88 (severe burden). Scores were further aggregated into two categories: ZCBI total score from 0 to 20 (without burden) and from 21 to 88 (with burden).

The Hospital Anxiety and Depression Scale (HADS) and the Beck Depression Inventory (BDI) were used to assess anxiety and depressive symptoms in patients with IPD and their caregivers. HADS consists of 7 items for the assessment of anxiety, and 7 items for the assessment of depression. A HADSAnxiety and Depression scale score of $\geq 10$ indicates risk of anxiety and scores $\geq 7$ indicate risk of depression. ${ }^{12}$ The BDI is a 21-item inventory and scores can range from 0 to 63 . Scores $\geq 17$ indicate risk for depression. ${ }^{13}$

The Short-Form Health Survey instrument (SF-36) was used to evaluate quality of life of the patients. The SF-36 includes 36 items covering 8 domains: physical function (PF, 10 items), role-physical (RP, 4 items), bodily pain (BP, 2 items), general health (GH, 5 items), vitality (VT, 4 items), social function (SF, 2 items), role-emotional (RE, 3 items), and mental health (MH, 5 items). Among them, physical functioning, physical role, pain, and general health belong to physical health, and emotional role, vitality, mental health, and social functioning belong to mental health. The scores range from 0 to 100 , with higher scores indicating better quality of life. ${ }^{14}$ The SF-36 Turkish standard version has been validated in our population. ${ }^{15}$ The Mini-Mental State Examination (MMSE) was administered to patients to evaluate the gross cognitive status. MMSE scores $>24$ were considered normal. ${ }^{16}$

\section{Ethical approval}

The study was approved by the Ethics Committee of Antalya Education and Research Hospital (No: 169). All participants gave written informed consent.

\section{Statistical analysis}

All statistical analyses were performed using the SPSS software package, version 21.0 for Windows (IBM Corp., Armonk, NY, USA). Demographic and baseline characteristics were summarized as mean \pm standard deviation (SD) for continuous variables and as the percentage of the group for categorical variables. Non-normally distributed data are presented as medians (inter-quartile range). Normality analysis was performed using the Kolmogorov-Smirnov test. The independent samples t-test was used to assess the differences between the groups (sex and health status). The Fisher's exact or Chi-square tests were used to compare the proportions. For the results, $\mathrm{p}<0.05$ was accepted as statistical significance.

\section{RESULTS}

\section{Patients}

Seventy-four patients (male, 58.1\%) were included in the study. The mean age of the patients was $66.18 \pm 8.5$. The mean duration of disease was $67.23 \pm 41.8$ months. The mean UPDRS score was $25.84 \pm 15.5$. According to the H\&Y scale, the 
patients were divided into two groups; stage I-II as early stage and stage III-V as late stage. Group 1 (H\&Y I-II) consisted of 40 patients and group 2 (H\&Y III-V) comprised 34 patients. The age and sex of these groups showed no significant differences. The mean duration of the disease and UPDRS scores were significantly higher in group $2(\mathrm{p}=0.003, \mathrm{p}=0.001$, respectively). Ten (25\%) patients in group 1 and 16 (47.1\%) patients in group 2 had off periods. The number of patients who had MMSE $<24$ and who had hallucinations were significantly higher in group 2 ( $\mathrm{p}=0.027, \mathrm{p}=0.002$, respectively). In group 1, nine $(22.5 \%)$ patients were receiving levodopa only, $10(25 \%)$ were receiving dopamine agonists only, and 21 (52.5\%) patients were receiving both. In group 2, nine (26.5\%) patients were receiving levodopa only, and 25 (73.5\%) were receiving both levodopa and dopamine agonists. No patients were receiving agonists only in group 2 . The demographic data of the patients are summarized in Table 1 .

There were no significant differences between group 1 and group 2 according to the HADS-Anxiety and HADS-Depression scales ( $\mathrm{p}=0.140, \mathrm{p}=0.641$, respectively); however, significant differences were found in group 2 according to the BDI $(\mathrm{p}=0.023)$ (Table 1).

The scores of SF-36 subdomains are shown in Table 2. There were significant differences between groups 1 and 2 according to the SF-36 subdomains such as general health, emotional role, social functioning, pain and mental health $(\mathrm{p}=0.019, \mathrm{p}=$ $0.038, \mathrm{p}=0.005, \mathrm{p}=0.004, \mathrm{p}=0.014$, respectively).

\section{Caregivers}

The mean age of the CGs in group 1 and group 2 was 46.65 15.75 and $49.41 \pm 14.32$ years, respectively. Both group 1 and group 2 were had a female predominance $(62.5 \%$ vs. $76.5 \%$,

Table 1. Demographic features of patients in group 1 and group 2

\begin{tabular}{|c|c|c|c|}
\hline Demographics & Group $1(\mathrm{~N}=40)$ & Group $2(\mathrm{~N}=34)$ & $\mathrm{p}$ value \\
\hline Age $($ mean $\pm S D)$, years & $66 \pm 8.6$ & $66.38 \pm 8.5$ & 0.849 \\
\hline Male sex, N (\%) & $24(60.0)$ & $19(55.9)$ & 0.721 \\
\hline Mean duration of disease (mean $\pm \mathrm{SD}$ ), months & $54.18 \pm 37.2$ & $82.59 \pm 42.2$ & 0.003 \\
\hline UPDRS (Mean \pm SD) & $20.3 \pm 11.3$ & $32.35 \pm 17.3$ & 0.001 \\
\hline Mini-Mental State Examination (<24), N (\%) & $3(7.5)$ & $9(26.5)$ & 0.027 \\
\hline Hallucination, N (\%) & & & 0.002 \\
\hline Insight $(+)$ & $4(10.0)$ & $7(20.6)$ & \\
\hline Insight (-) & $1(2.5)$ & $8(23.5)$ & \\
\hline Medication, N (\%) & & & 0.063 \\
\hline Monotherapy & $19(47.5)$ & $9(26.5)$ & \\
\hline Polytherapy & $21(52.5)$ & $25(73.5)$ & \\
\hline BECK Depression Scale ( $\geq 17), \mathrm{N}(\%)$ & $6(15.0)$ & $13(38.2)$ & 0.023 \\
\hline HADS-Depression Scale ( $\geq 7), \mathrm{N}(\%)$ & $19(47.5)$ & $18(52.9)$ & 0.641 \\
\hline HADS-Anxiety Scale ( $\geq 10), \mathrm{N}(\%)$ & $8(20.0)$ & $12(35.3)$ & 0.140 \\
\hline
\end{tabular}

N: number, SD: standard deviation, UPDRS: Unified Parkinson's Disease Rating Scale, HADS: The Hospital Anxiety and Depression Scale

Table 2. SF-36 sub-domain scores of patients

\begin{tabular}{lccc}
\hline \multicolumn{1}{c}{ SF-36 sub-domains } & Group 1 & Group 2 & p value \\
\hline General health (mean, SD) & $52.57 \pm 21.26$ & $41.32 \pm 18.8$ & 0.019 \\
Physical functioning (mean, SD) & $57.72 \pm 29.7$ & $45.29 \pm 30.02$ & 0.078 \\
Physical role (median, IQR) & $75(0-100)$ & $0(0-100)$ & 0.077 \\
Emotional role (median, IQR) & $100(0-100)$ & $0(0-100)$ & $0.038^{*}$ \\
Social functioning (median, IQR) & $100(50-100)$ & $50(25-100)$ & $0.005^{*}$ \\
Pain (median, IQR) & $100(72.5-100)$ & $61(32-100)$ & $0.004^{*}$ \\
Mental health (mean, SD) & $69.85 \pm 18.67$ & $57.47 \pm 23.71$ & $0.014^{*}$ \\
Vitality (mean, SD) & $47.87 \pm 23.11$ & $43.97 \pm 23.73$ & 0.477 \\
SF-36 (physical) (median, IQR) & $67(43.25-83.43)$ & $42.12(31.06-64.18)$ & $0.005^{*}$ \\
SF-36 (mental) (median, IQR) & $64.37(47.37-83.50)$ & $39.50(30.12-74.18)$ & $0.009^{*}$ \\
\hline
\end{tabular}

*Mann-Whitney U test. SF-36: The Short -Form Health Survey instrument, SD: standard deviation, IQR: inter quartile range 
respectively), but there were no significant differences between the two groups. The relations of the caregiver to the patient were as follows: in group 1, 22 (55\%) were their children, 18 (45\%) were spouses; in group 2, $17(50 \%)$ were their children, $16(47.1 \%)$ were spouses, and $1(2.9 \%)$ was a paid CG. In group 1, 33 (82.5\%) CGs were living in the city, 7 (17.5\%) in a suburban area, and in group 2, 30 (88.2\%) CGs were living in the city, and $4(11.8 \%)$ in a suburban area. There were no significant differences between groups 1 and 2 according to places that the CGs lived ( $\mathrm{p}=0.787$ ).

Only one (2.9\%) caregiver wanted to institutionalize their patient in a nursing home because of advanced stage IPD.

Nine (22.5\%) CGs had a BDI score of $\geq 17$ in group 1, whereas $3(8.8 \%)$ had a BDI score of $\geq 17$ in group 2. HADS-Depression scale scores $\geq 7$ were observed in 11 (27.5\%) CGs in group 1, compared with 10 (29.4\%) CGs in group 2. HADSAnxiety scale scores $\geq 10$ were observed in 11 (27.5\%) CGs in group 1, whereas it was 4 (11.8\%) CGs in group 2 (Table 3).

According to the ZCBI, in group 1, 21 (52.5\%) CGs described no burden, 15 (37.5\%) had mild burden, and 4 (10\%) had severe burden. In group 2, 18 (52.9\%) CGs described no burden, 12 (35.3\%) had mild burden, and 4 (11.8\%) had severe burden; however, there were no significant differences between the two groups concerning $\mathrm{CB}(\mathrm{p}=0.970)$ (Table 3).

When evaluating the $\mathrm{CB}$ according to another 2 groups such as total score of 0 to 20 (without burden) and from 21 to 88 (with burden), we found no burden in 39 (52.7\%) CGs and burden in 35 (47.3\%) CGs. There were no significant differences between these groups according to CGs' and patients' sex, relations between patients and CGs, employment status, dementia and hallucinations, duration of the disease, UPDRS scores, medications, and the time spent with their patients (Table 4). The number of patients who had BDI scores of $\geq 17$ was significantly higher in CGs with burden $(p=0.008)$. Similarly, CGs who had BDI scores of $\geq 17$ and HADS-Depression Scale scores of $\geq 7$ were significantly higher among CGs with burden ( $\mathrm{p}=0.036$ ). When evaluating the SF-36 as physical components and mental components, there were significant differences in quality of life according to the group with burden ( $\mathrm{p}=$ $0.008, \mathrm{p}<0.0001$, respectively).

\section{DISCUSSION}

Although CB was found in 35 (47.3\%) caregivers in our study, we found no significant differences between the caregivers of patients with early and late-stage IPD. We thought that this might be due to the strong family relationships and cultural dynamics in Turkey.

In our country, the CGs of these patients are usually their family members, mostly their children or spouses. Except for
Table 3. Demographic features of caregivers of group 1 and group 2

\begin{tabular}{|c|c|c|c|}
\hline CG demographics & $\begin{array}{l}\text { Group } 1 \\
(\mathrm{~N}=40)\end{array}$ & $\begin{array}{l}\text { Group } 2 \\
(\mathrm{~N}=34)\end{array}$ & $\begin{array}{c}\mathrm{p} \\
\text { value }\end{array}$ \\
\hline Age $($ mean $\pm S D)$, years & $46.65 \pm 15.75$ & $49.41 \pm 14.32$ & 0.436 \\
\hline Female sex, N (\%) & $25(62.5)$ & $26(76.5)$ & 0.196 \\
\hline Education degree, N (\%) & & & 0.585 \\
\hline Primary school & $26(65.0)$ & $20(58.8)$ & \\
\hline High school & $11(27.5)$ & $5(14.7)$ & \\
\hline University & $3(7.5)$ & $9(26.5)$ & \\
\hline Employment, N (\%) & & & 0.609 \\
\hline Employed & $14(35.0)$ & $10(29.4)$ & \\
\hline Unemployed & $1(2.5)$ & $5(14.7)$ & \\
\hline Retired & $6(15.0)$ & $6(17.6)$ & \\
\hline Housewife & $19(47.5)$ & $13(38.2)$ & \\
\hline Marital status, N (\%) & & & 0.350 \\
\hline Married & $33(82.5)$ & $25(73.5)$ & \\
\hline Relationship status, N (\%) & & & 0.859 \\
\hline Children & $22(55.0)$ & $17(50.0)$ & \\
\hline Spouse & $18(45.0)$ & $16(47.1)$ & \\
\hline Paid caregiver & & $1(2.9)$ & \\
\hline Duration of caregiving, N (\%) & & & 0.231 \\
\hline$>3$ months & $39(97.5)$ & $31(91.2)$ & \\
\hline Time spent caregiving, N (\%) & & & 0.112 \\
\hline Multiple hours & $13(32.5)$ & $8(23.5)$ & \\
\hline During daytime & $6(15.0)$ & $2(5.9)$ & \\
\hline Night and day & $21(52.5)$ & $24(70.6)$ & \\
\hline $\begin{array}{l}\text { BECK Depression Scale } \\
(\geq 17), N(\%)\end{array}$ & $9(22.5)$ & $3(8.8)$ & 0.112 \\
\hline $\begin{array}{l}\text { HADS-Depression Scale } \\
(\geq 7), N(\%)\end{array}$ & $11(27.5)$ & $10(29.4)$ & 0.856 \\
\hline $\begin{array}{l}\text { HADS-Anxiety Scale } \\
(\geq 10), \mathrm{N}(\%)\end{array}$ & $11(27.5)$ & $4(11.8)$ & 0.93 \\
\hline ZCBI & & & 0.970 \\
\hline Little or no burden & $21(52.5)$ & $18(52.9)$ & \\
\hline Mild to moderate burden & $15(37.5)$ & $12(35.3)$ & \\
\hline Moderate to severe burden & $2(5.0)$ & $3(8.8)$ & \\
\hline Severe burden & $2(5.0)$ & $1(2.9)$ & \\
\hline
\end{tabular}

CG: caregiver, N: number, SD: standard deviation, HADS: The Hospital Anxiety and Depression Scale, ZCBI: Zarit Caregiver Burden Inventory

one paid CG, all of the CGs in our study were family members including spouses or children. Similar to previous reports, CGs were mainly females $(68.9 \%$,) especially wives and daughters. ${ }^{17-20}$ The patriarchal system has been more prevalent in our country; therefore, according to Turkish social and cultural characteristics, females usually perform caregiving tasks. Traditionally, caregiving tasks were mostly nursing at home, caring 
Table 4. Evaluation of characteristics related to disease according to Zarit Scale

\begin{tabular}{|c|c|c|c|}
\hline & \multicolumn{2}{|c|}{ Zarit caregiver burden scale } & \multirow{3}{*}{$\mathrm{p}$ value } \\
\hline & Without burden & With burden & \\
\hline & $\mathrm{N}=39(52.7 \%)$ & $\mathrm{N}=35(47.3 \%)$ & \\
\hline Age $($ mean $\pm S D)$, years & $48.7 \pm 16.2$ & $47.06 \pm 13.9$ & 0.645 \\
\hline Female sex, patient, N (\%) & $17(43.6)$ & $14(40.0)$ & 0.755 \\
\hline Female sex, caregiver, N (\%) & $25(64.1)$ & $26(74.3)$ & 0.345 \\
\hline Wife, N (\%) & $18(46.2)$ & $16(45.7)$ & 0.970 \\
\hline Children, N (\%) & $21(53.8)$ & $18(51.4)$ & 0.835 \\
\hline Unemployed caregivers, N (\%) & $27(69.2)$ & $23(65.7)$ & 0.747 \\
\hline Patient with dementia, N (\%) & $5(12.8)$ & $7(20.0)$ & 0.403 \\
\hline Patient with hallucination, N (\%) & $9(23.1)$ & $11(31.4)$ & 0.419 \\
\hline Medication, polytherapy, N (\%) & $26(66.7)$ & $20(57.1)$ & 0.399 \\
\hline Mean duration of disease (mean $\pm \mathrm{SD})$, months & $62.54 \pm 30.7$ & $72.46 \pm 51.39$ & 0.311 \\
\hline UPDRS score (mean \pm SD) & $22.56 \pm 15.24$ & $29.49 \pm 15.26$ & 0.055 \\
\hline \multicolumn{4}{|l|}{ Total duration of caregiving, N (\%) } \\
\hline$>3$ month & $37(94.9)$ & $33(94.3)$ & 1 \\
\hline \multicolumn{4}{|l|}{ Hours for caregiving, N (\%) } \\
\hline Night and day & $25(64.1)$ & $20(57.1)$ & 0.540 \\
\hline BDI Scale ( $\geq 17)$, patient, N (\%) & $5(12.8)$ & $14(40.0)$ & 0.008 \\
\hline BDI Scale ( $\geq 17)$, caregiver, N (\%) & $3(7.7)$ & $9(25.7)$ & 0.036 \\
\hline HADS-Depression Scale ( $\geq 7), \mathrm{N}(\%)$ & $5(12.8)$ & $16(45.7)$ & 0.002 \\
\hline HADS-Anxiety Scale ( $\geq 10)$, N (\%) & $5(12.8)$ & $10(28.6)$ & 0.092 \\
\hline SF-36 (physical) (mean, SD) & $62.57 \pm 22.6$ & $47.41 \pm 24.8$ & 0.008 \\
\hline SF-36 (mental) (median, IQR) & $68.65(50-87.50)$ & $39.75(28.62-58.50)$ & $<0.001^{*}$ \\
\hline
\end{tabular}

*Mann-Whitney U test. N: number, SD: standard deviation, IQR: inter quartile range, UPDRS: Unified Parkinson's Disease Rating Scale, HADS: The Hospital Anxiety and Depression Scale, SF-36: The Short-Form Health Survey instrument

or cleaning. According to cultural psychosocial effects and our beliefs, they usually adapt to the diseases' state and accept this dependence. Therefore, the reason why there were no differences concerning burden between the early and late stages of the disease could be that the CGs perceived this condition as a task or obligation. Thus, under these circumstances, apart from the stage of the disease or progression, they had to continue caregiving. Again, according to our traditions, institutionalization is a non-preferred behavior. Thus, the proportion of caregivers who wanted to institutionalize their patients in a nursing home was very low, only one person wanted to institutionalize their patient and the patient was in advanced stage and had neuropsychiatric symptoms.

Previous studies showed significant differences between increased burden and disease duration, duration of caregiving, caregiving hours, H\&Y stage, and hallucinations. ${ }^{8}$ In contrast, we found a significant difference in depression scores between the groups with and without burden. Depression is known to have a major impact on the prognosis of PD. In one review, the prevalence of major depression in IPD was found as $17 \%$, minor depression was $22 \%$, and dysthymia $13 \%{ }^{21}$ Similar to these results, depressive symptoms were found as $15 \%$ in group 1, whereas it was $38 \%$ in group 2. Burden was found to be higher in depressive patients' CGs and CGs who had depressive symptoms.

IPD could negatively affect the patients' or CGs' quality of life by enhancing the stress and burden. ${ }^{22}$ Compared with the general population, mostly physical and social functioning subdomains could be affected. ${ }^{23}$ Our study showed significant differences between patients in groups 1 and 2 concerning general health, pain, emotional role, mental health, and social function. As expected, the scores were lower in group 2 (latestage patients), so they had a lower quality of life. Additionally, the affected subdomains of SF-36 reflected that as well as the physical health, mental health could commonly be affected in the late stages of IPD. Our results showed a statistically significant difference between burden and SF-36 physical and mentally-related aspects. Depression could increase fatigue, decrease motivation, decrease independency, and decrease capacity of daily living activities. Thus, the need for a CG increas- 
es and the positive effects of caregiving remains limited. ${ }^{24-26}$ CGs' depression also affects burden. Furthermore, the prevalence of anxiety in IPD was found as $25-40 \%$ and mostly observed with depressive symptoms. ${ }^{27,28}$ In some studies, depressive symptoms in CGs were reported as $40-50 \%$ and anxiety was $30 \% .^{18,19,23,29}$ Some other studies showed a correlation between non-motor symptoms, especially depressive symptoms and anxiety, in patients and CGs with burden. ${ }^{6,25,26}$ However, we found no significant differences concerning anxiety scores between patients in groups 1 and 2. Additionally, we found no correlation between anxiety and burden in CGs. These findings might be resulted as depressive symptoms might not be accompanied every time with anxiety. The duration of disease and disability could increase CGs depressive symptoms. ${ }^{17,23,30}$ However, Lökk ${ }^{19}$ reported an unexpected result as the general health condition of the CGs was regarded satisfactory independent of disease duration. This condition might be related to CGs' adaptation to strain and burden, and also might depend on learning to cope with these issues. In addition, they feel satisfaction by fulfilling the sense of mission by caring a patient. In concert with these findings, we found no significant differences between the duration of disease and burden. Additionally, we thought that our traditional characteristics might impacted on this situation. Some studies suggested that CB would differ according to their relationship to the patient because age and socioeconomic conditions could be different between spouses and children who are responsible for caring. ${ }^{2}$ However, we found no significant differences between these two groups concerning burden. Similar to Lökk ${ }^{19}$ study, there was no significant relationship between CG's age and burden. Another study suggested that spousal CGs' sex had no impact on CG's mental health. ${ }^{31}$

Depressive symptoms of patients with IPD are one of the main contributors that increase CB. Independent from the stage of the disease, the presence of depression is likely to be related to CG's burden and depressive symptoms. When managing the treatment of patients, we also have to consider the $\mathrm{CB}$ and quality of life. It is important to recognize depressive symptoms earlier to protect the relationship between the CG and the patient because the main providers of care are family members. If necessary, we should recommend protective treatment earlier.

\section{Conflicts of Interest}

The authors have no potential conflicts of interest to disclose.

\section{REFERENCES}

1. Martinez-Martin P, Rodriguez-Blazquez C, Forjaz MJ, Frades-Payo B, Agüera-Ortiz L, Weintraub D, et al. Neuropsychiatric symptoms and caregiver's burden in Parkinson's disease. Parkinsonism Relat Disord 2015;21:629-634.
2. Shin H, Lee JY, Youn J, Kim JS, Cho JW. Factors contributing to spousal and offspring caregiver burden in Parkinson's disease. Eur Neurol 2012;67:292-296.

3. Tessitore A, Marano P, Modugno N, Pontieri FE, Tambasco N, Canesi $\mathrm{M}$, et al. Caregiver burden and its related factors in advanced Parkinson's disease: data from the PREDICT study. J Neurol 2018;265:1124-1137.

4. Ozdilek B, Gunal DI. Motor and non-motor symptoms in Turkish patients with Parkinson's disease affecting family caregiver burden and quality of life. J Neuropsychiatry Clin Neurosci 2012;24:478-483.

5. Balash Y, Korczyn AD, Knaani J, Migirov AA, Gurevich T. Quality-oflife perception by Parkinson's disease patients and caregivers. Acta Neurol Scand 2017;136:151-154.

6. Torny F, Videaud H, Chatainier P, Tarrade C, Meissner WG, Couratier P. Factors associated with spousal burden in Parkinson's disease. Rev Neurol (Paris) 2018;174:711-715.

7. Hiseman JP, Fackrell R. Caregiver burden and the nonmotor symptoms of Parkinson's disease. Int Rev Neurobiol 2017;133:479-497.

8. Zhong M, Peppard R, Velakoulis D, Evans AH. The relationship between specific cognitive defects and burden of care in Parkinson's disease. Int Psychogeriatr 2016;28:275-281.

9. Yuksel B, Ak PD, Sen A, Sariahmetoglu H, Uslu SC, Atakli D. Caregiver burden and quality of life in early stages of idiopathic Parkinson's disease. Ideggyogy Sz 2018;71:343-350.

10. Hoehn MW, Yahr MD. Parkinsonism: onset, progression and mortality. Neurology 1967;17:427-442.

11. Zarit SH, Orr NK, Zarit JM. The Hidden Victims of Alzheimer's Disease; Families under Stress. New York: New York University Press; 1985.

12. Aydemir Ö, Güvenir T, Küey L, Kültür S. Hastane anksiyete ve depresyon ölçeği Türkçe formunun geçerlilik ve güvenilirliği. Türk Psikiyatri Dergisi 1977;8:280-287.

13. Hisli N. Beck Depresyon envanterinin üniversite öğrencileri için geçerliği, güvenirliği. Psikoloji Dergisi 1989;7:3-13.

14. Ware JE Jr, Sherbourne CD. The MOS 36-item short-form health survey (SF-36). I. Conceptual framework and item selection. Med Care 1992; 30:473-483.

15. Kocyigit H, Aydemir O, Olmez N, Memis A. Reliability and validity of the Turkish version of Short-Form-36 (SF-36). Turkish J Drugs Therap 1999;12:102-106.

16. Folstein MF, Folstein SE, McHugh PR. 'Mini-Mental State' a practical method for grading the cognitive state of patients for the clinician. J Psychiatr Res 1975;12:189-198.

17. Schrag A, Hovris A, Morley D, Quinn N, Jahanshahi M. Caregiver-burden in Parkinson's disease is closely associated with psychiatric symptoms, falls, and disability. Parkinsonism Relat Disord 2006;12:35-41.

18. Martinez-Martin P, Forjaz MJ, Frades-Payo B, Rusinol AB, FernandezGarcia JM, Benito-Leon J, et al. Caregiver burden in Parkinson's disease. Mov Disord 2007;22:924-931.

19. Lökk J. Caregiver strain in Parkinson's disease and the impact of disease duration. Eur J Phys Rehabil Med 2008;44:39-45.

20. Carod-Artal FJ, Mesquita HM, Ziomkowski S, Martinez-Martin P. Burden and health related quality of life among caregivers of Brazilian Parkinson's disease patients. Parkinsonism Relat Disord 2013;19:943-948.

21. Reijnders JS, Ehrt U, Weber WE, Aarsland D, Leentjens AF. A systematic review of prevalence studies of depression in Parkinson's disease. Mov Disord 2008;23:183-189.

22. Carter JH, Stewart BJ, Lyons KS, Archbold PG. Do motor and nonmotor symptoms in PD patients predict caregiver strain and depression? Mov Disord 2008;23:1211-1216.

23. Schrag A, Jahanshahi M, Quinn N. How does Parkinson's disease affect quality of life? A comparison with quality of life in general population. Mov Disord 2000;15:1112-1118.

24. Mosley PE, Moodie R, Dissanayaka N. Caregiver burden in Parkinson disease: a critical review of recent literature. J Geriatr Psychiatry Neurol 2017;30:235-252.

25. Sanyal J, Das S, Ghosh E, Banerjee TK, Bhaskar LV, Rao VR. Burden 
among Parkinson's disease care givers for a community based study from India. J Neurol Sci 2015;358:276-281.

26. Larsen JP, Dalen I, Pedersen KF, Tysnes OB. The natural history of depressive symptoms in patients with incident Parkinson's disease: a prospective cohort study. J Neurol 2017;264:2401-2408.

27. Simuni T, Fernandez HH. Anxiety in Parkinson's Disease. In: Pfeiffer RF, Bodis-Wollner I, Editors. Parkinson's Disease and Nonmotor Dysfunction, Second Edition. New York: Humana Press, 2013, p.17e29.

28. Nègre-Pagès L, Grandjean H, Lapeyre-Mestre M, Montastruc JL, Fourrier A, Lépine JP, et al. Anxious and depressive symptoms in Parkinson's disease: the French cross-sectionnal DoPaMiP study. Mov Disord 2010;
25:157-166.

29. Aarsland D, Larsen JP, Karlsen K, Lim NG, Tandberg E. Mental symptoms in Parkinson's disease are important contributors to caregiver distress. Int J Geriatr Psychiatry 1999;14:866-874.

30. Fernandez HH, Tabamo RE, David RR, Friedman JH. Predictors o depressive symptoms among spouse caregivers in Parkinson's disease. Mov Disord 2001;16:1123-1125.

31. Hooker K, Manoogian-O’Dell M, Monahan DJ, Frazier LD, Shifren K. Does type of disease matter? Gender differences among Alzheimer's and Parkinson's disease spouse caregivers. Gerontologist 2000;40:568-573. 